Fecha de recepción: marzo 2020 Fecha de aceptación: abril 2020 Versión final: junio 2020

\section{El camino de las heroínas negras: Blaxploitation}

Sara Müller ${ }^{(1)}$

Resumen: En Estados Unidos el feminismo no surgió de las mujeres que de forma más directa eran víctimas de la opresión sexista; mujeres golpeadas a diario, mental, física y espiritualmente; mujeres sin la fuerza necesaria para cambiar sus condiciones de vida" (Hooks, 2004, p.33). Las activistas feministas eran blancas y burguesas, mientras que las mujeres negras eran una mayoría silenciosa.

Si bien muchas mujeres participaron del Black Power, el movimiento era definido y articulado en los medios, la cultura popular y las artes por hombres. Los grupos mantenían una organización patriarcal, estructuras caracterizadas por el liderazgo masculino. Ellas "tomaron conciencia de la naturaleza de la dominación masculina cuando militaban en espacios anticlasistas y antirracistas con hombres que hablaban al mundo sobre la importancia de la libertad mientras subordinaban a las mujeres en sus filas" (Hooks, 2017, p.22). Había un no lugar destinado para las mujeres negras entre las feministas blancas y el Black Power de los hombres.

"Como grupo, las mujeres negras están en una posición inusual en esta sociedad, pues no sólo estamos como colectivo en el fondo de la pirámide ocupacional, sino que nuestro estatus social es más bajo que el de cualquier otro grupo. Al ocupar esta posición, aguantamos lo más duro de la opresión sexista, racista y clasista. [...] Los hombres negros pueden ser víctimas de racismo, pero el sexismo les permite actuar como explotadores y opresores de las mujeres. Las mujeres blancas pueden ser víctimas del sexismo, pero el racismo les permite actuar como opresoras de la gente negra" (Hooks, 2004, p.49).

En este contexto político-social, surge a fines de los 60's la Blaxploitation en el cine estadounidense, que reemplazaría viejos estereotipos de sumisión por nuevos de hipersexualidad, violencia antisocial, comunidades sin ley, dominadas por la corrupción y el vicio, como una versión caricaturizada del Black Power que ha sido muy reprochada en casi todos sus aspectos por contrarrevolucionaria y antitética a la liberación de la comunidad afroamericana (Terry, 2012). Pero incluso los más duros críticos reivindican el lugar de las heroínas negras entre la violencia y los estereotipos de la Blaxploitation.

En los albores de las películas Blaxploitation, las mujeres quedaban otra vez al margen. Sin embargo, Pam Grier, Tamara Dobson, Teresa Graves y Jeannie Bell pavimentaron el camino para nuevas heroínas y redefinieron a la mujer en la pantalla. La contribución de estas actrices a la cultura pop y al cine en general es monumental, alejándose de los papeles clásicos como Mammy (esclava de las plantaciones del Sur que servía en la casa cumpliendo tareas domésticas o como cocinera, gorda y asexuada) y como Sapphire (combativa verbalmente, gesticulando, apuntando con un dedo a su marido y con la otra mano en la cadera), entre muchos otros (Sims, 2006). 
Durante el período Blaxploitation la heroína de acción era una mujer común, hasta el momento ese lugar femenino era una ausencia cinematográfica, antecedente valioso que sería retomado por el mainstream en la Ellen Ripley de Alien (1979), la Sarah Connor de Terminator (1984), Thelma y Louis (1991) (Sims, 2006).

Queremos pensar el cine como valioso punto de análisis de la historia, como documento de época, como artefacto cultural. Las películas tienen el poder de dar forma, reforzar, o lisa y llanamente deconstruir las percepciones sobre etnias, géneros, clases, sexualidades. Poderosos transmisores comunicacionales, las películas jugaron y juegan un importante papel sobre los mitos culturales respecto a lo femenino.

Palabras claves: Movimientos feministas - Black Power - Blaxploitation - heroínas negras - estereotipos - mitos culturales.

[Resúmenes en inglés y portugués en la páginas 70-72]

${ }^{(1)}$ Sara Müller. Doctoranda del Programa Interuniversitario de Doctorado en Educación (UNTREF, UNSAM, UNLA). Profesora en Docencia Superior (UTN-2014). Magíster y Especialista en Educación, lenguajes y medios (UNSAM-2013). Licenciada en Comunicación Audiovisual (UNSAM-2001). Productora y Directora de radio y televisión (ISER1996). Se desempeña como docente de las asignaturas: Taller de Creación III (UP); Proyecto cinematográfico (UB); Asistencia de Dirección y Producción de TV y Técnicas Operativas de estudio de TV. CENS Nº 69 - Canal 7.

\section{Introducción}

Este texto iba a comenzar con una frase del estilo: "En la década del sesenta el mundo era otro mundo, distinto del que conocemos hoy, no era el mismo"... o algo así. Repensando la línea, no estamos tan seguros de esa taxatividad. Paradójicamente, hoy a nivel mundial continuamos enfrentando problemas producto de "las promesas incumplidas de la modernidad: libertad, igualdad, solidaridad y paz [...] para los cuales parece no haber soluciones modernas" (De Sousa Santos, 2003 citado por Álvarez Ossa, 2015, p.22).

Las mujeres en general seguimos siendo víctimas de la violencia de género, seguimos desafiando los techos de cristal en muchos ámbitos y según la clase social, etnia, orientación sexual la cosa empeora superlativamente. Pero también es innegable una luz de esperanza, las sociedades se mueven y reflexionan de la mano de la acción política de innumerables colectivos que en todo el mundo dicen: “¡Basta!”.

Antes de comenzar con el tema foco, el camino de las heroínas negras durante el período denominado Blaxploitation, queremos recuperar el contexto y darle un marco, sin pretensión de revisionismo histórico alguno, pero sí para dimensionar el fenómeno con 
algunos datos. Dieciocho años antes (1955) de las tres películas icónicas que tomaremos para este escrito, Rosa Parks era detenida en Alabama mientras viajaba de regreso a casa, por no cederle su asiento en el autobús a un blanco. Alrededor de diez años antes (1963) de estas películas protagonizadas por hermosísimas mujeres afroamericanas, era asesinado Medgar Evers delante de su familia por un activista del Ku Klux Klan. Evers, militante por los derechos civiles, muere a causa del disparo pero también por negársele el ingreso al hospital "solo para blancos", en plena época de racismo lacerante donde el acceso a viviendas, escuelas, sanitarios, etcétera, etcétera, etcétera, estaba prohibido para los "colored". Nueve años antes (1965) de nuestras películas, es asesinado Malcolm X en Nueva York. Seis años antes (1967) la Corte Suprema declara inconstitucional la ley que prohíbe el matrimonio interracial. Cinco años antes (1968) es asesinado en Memphis Martin Luther King.

En 1960 se dio un renacer de la lucha de los afroestadounidenses por el reconocimiento de sus derechos políticos y por el fin de la segregación racial. Bajo el liderazgo de Martin Luther King, Malcom X, Rosa Parks, Huey P. Newton y Bobby Seale, la integración era posible y necesaria. Los defensores del Black Power querían definir su destino sin depender de los blancos.

Belucci (2013) dibuja la década del sesenta como aquella que "desde las entrañas del capitalismo avanzado se escucharon y se vivieron luchas contra todo tipo de opresión: manifestaciones de la comunidad negra por la conquista de sus derechos civiles, estudiantes, mujeres, homosexuales junto a un poderoso movimiento antibelicista" (p.1). Cada grupo fue descubriendo la naturaleza de su dominación dentro de la sociedad norteamericana. En este contexto político-social que hemos apretadamente resumido, surge a fines de los 60's la Blaxploitation en el cine estadounidense, que reemplazaría viejos estereotipos de sumisión por nuevos de hipersexualidad, violencia antisocial, comunidades sin ley, dominadas por la corrupción y el vicio, como una versión caricaturizada del Black Power que ha sido muy reprochada en casi todos sus aspectos por contrarrevolucionaria y antitética a la liberación de la comunidad afroamericana (Terry, 2012). Sin embargo, la Blaxploitation logra dar visibilidad a los movimientos de lucha contra la segregación y arrojar al olvido a las "Mammies" y a los "Little Black Sambos" que hasta entonces poblaban las pantallas (ibíd.). Y esto no es baladí, ya que las representaciones cinematográficas coinciden a menudo con "una exacerbación del problema de la afirmación y la disputa por las identidades culturales y raciales, dentro de complejos procesos políticos y sociales" (Goyeneche-Gómez, 2012, p.389).

Queremos pensar el cine como valioso punto de análisis de la historia, como documento de época, como artefacto cultural. Las películas tienen el poder de dar forma, reforzar, endurecer o lisa y llanamente deconstruir las percepciones sobre etnias, géneros, clases, sexualidades. Así, las películas como poderosos transmisores comunicacionales, jugaron y juegan un importante papel sobre los mitos culturales respecto a lo femenino, y en este sentido, incluso los más crueles críticos reivindican el lugar de las heroínas negras entre la violencia y los estereotipos de la Blaxploitation. Creemos por eso, y a modo de iluminar el posicionamiento, que la realidad de las mujeres negras en los años sesenta y setenta merece un apartado propio para dar comienzo al desarrollo de este paper. 


\section{Desarrollo}

\section{Derechos civiles, feminismos y mujeres negras}

En paralelo a los movimientos por la igualdad racial comienzan a levantar la voz los movimientos feministas. Sin embargo, "en Estados Unidos el feminismo no surgió de las mujeres que de forma más directa eran víctimas de la opresión sexista; mujeres golpeadas a diario, mental, física y espiritualmente; mujeres sin la fuerza necesaria para cambiar sus condiciones de vida" (Hooks, 2004, p.33). Las activistas feministas eran blancas y burguesas, y las mujeres negras eran una mayoría silenciosa.

La crítica de Hooks (2004) hacia varios movimientos feministas de la época se centra en la falta de interés por las necesidades de las mujeres sin ninguna posibilidad de elegir. Movimientos que, en su mayoría, ignoraban la existencia de mujeres que no fueran blancas, así como también de las mujeres blancas pobres. Los problemas y dilemas de las amas de casa blancas eran reales, pero no eran problemas políticos que afectaran a la gran cantidad de mujeres que vivían preocupadas por la supervivencia económica y la discriminación racial. Hooks (ibíd.) agrega:

Cuando participé en grupos feministas, descubrí que las mujeres blancas adoptaban una actitud condescendiente hacia mí y hacia otras participantes no blancas. La condescendencia que dirigían a las mujeres negras era una forma de recordarnos que el movimiento era «suyo», que podíamos participar porque ellas lo permitían, incluso nos alentaban a hacerlo. Después de todo, teníamos que legitimar el proceso. No nos veían como iguales. No nos trataban como a iguales. (p. 45)

Hooks (2004) también dedica varias líneas al sexismo de los hombres negros, que a su entender ha socavado las luchas por los derechos civiles "del mismo modo que el racismo de las mujeres blancas ha socavado las luchas feministas" (p.49) .Si bien muchas mujeres participaron del Black Power, el movimiento era definido y articulado en los medios, la cultura popular y las artes por hombres. Los grupos mantenían una organización patriarcal, estructuras caracterizadas por el liderazgo masculino.

"Elaine Brown, Angela Davis, Sarah Evans, Mary King y muchas otras presentaron un desafío a la retórica de la liberación y la revolución derivada de las nociones masculinas del Black Power" (Terry, 2012, p.87). Las mujeres encarnaban las contradicciones del movimiento: eran golpeadas y encarceladas junto a los hombres, y a pesar de que se les concedieron roles que podrían considerarse importantes en algunos niveles, eran marginadas en las jerarquías internas y los medios de comunicación que privilegiaban las opiniones masculinas (Terry, 2012).

Trayce Matthews mantiene una posición similar sobre las "políticas de género" que afectaban la habilidad del partido para erigirse como organización política. En grupos como los Panteras Negras, CORE, Black Muslims cuyo objetivo era la "liberación", las mujeres negras eran activamente relegadas (ibíd.). Ellas "tomaron conciencia de la naturaleza de la dominación masculina cuando militaban en espacios anticlasistas y antirracistas con 
hombres que hablaban al mundo sobre la importancia de la libertad mientras subordinaban a las mujeres en sus filas" (Hooks, 2017, p.22). Había un no lugar destinado para las mujeres negras entre las feministas blancas y el Black Power de los hombres.

Como grupo, las mujeres negras están en una posición inusual en esta sociedad, pues no sólo estamos como colectivo en el fondo de la pirámide ocupacional, sino que nuestro estatus social es más bajo que el de cualquier otro grupo. Al ocupar esta posición, aguantamos lo más duro de la opresión sexista, racista y clasista. [...] Los hombres negros pueden ser víctimas de racismo, pero el sexismo les permite actuar como explotadores y opresores de las mujeres. Las mujeres blancas pueden ser víctimas del sexismo, pero el racismo les permite actuar como opresoras de la gente negra. (Hooks, 2004, p.49)

Hooks (2004) también afirma que las discusiones por las diferencias de clase en los movimientos feministas surgieron antes que las discusiones raciales. Sin embargo, también sostiene que "la lucha de clases está unida de forma inseparable a la lucha para terminar con el racismo" (p.36).

En este sentido, una de las contribuciones más importantes de las mujeres negras a las teorías feministas es la interseccionalidad entendida como la vivencia común de dos o más sistemas de discriminación (patriarcalismo, racismo, clasismo, sexismo, heterosexismo), no excluyentes entre sí, que coexisten y se interrelacionan, que operan simultáneamente, produciendo una realidad de desigualdad e impactando negativamente en la vida de las mujeres. "Género, clase y raza tienen una naturaleza interconectada" (Carneiro, 2001 citada por Álvarez Ossa, 2015, p.31). No despreciar ninguno de los aspectos de estas categorías nos permite avanzar en la comprensión de la problemática de las mujeres negras, puesto que todas tienen lugar al mismo tiempo dentro de una realidad compleja, produciendo efectos de opresión y anulación de los derechos humanos. "Para Ochy Curiel (2002) superponer una de estas categorías por sobre las otras es un error político que ha dado al sistema herramientas para generar mayor segregación y exclusión" (ibíd., p.31). Habiendo establecido hasta aquí algunos parámetros, queremos definir a continuación de qué hablamos cuando hablamos de Blaxploitation, para luego sí adentrarnos en el camino de nuestras heroínas negras.

\section{Erase una vez la Blaxploitation}

La Blaxploitation fue un movimiento cinematográfico "convertido en fenómeno social en los Estados Unidos de los años 70" (Narcea, 2015, p.1). Como muchos otros géneros, según Altman (1999), no tiene un punto de origen estable ni definido, pero se "identificó como categoría cultural durante el período liberal posterior al movimiento pro-derechos civiles" (p.133). Blaxploitation es la palabra resultante de comprimir los vocablos "black" y "exploitation". En los "todo por descubrir" años cuarenta, sobre las ruinas aún humeantes de la Segunda Guerra Mundial, Hollywood esperaba incrementar el número de espectadores y comenzó a producir películas que históricamente el mainstream había 
despreciado (Hartman, 1994 citado por Harris y Mushtaq, 2013). Así empezaron a desfilar por las pantallas de los grindhouse monstruos varios, caníbales, peleas de kung fu, motociclistas, rumberas, temas médicos controvertidos para la época, sexo suave y no tanto, $\mathrm{y}$ a veces todo junto. A esta miscelánea de bizarreces se la llamó cine de explotación o exploitation. Ed Guerrero (1993) define la Blaxploitation como "the production of the sixty or so Hollywood films that centered on Black narratives, featured Black casts playing out various action-adventures in the ghetto, and were released roughly between 1969 and 1974" (Guerrero, 1993 citado por Harris y Mushtaq, 2013, p. 33).

Antes también hubo películas de "negros". En los años treinta se estrenaron varios títulos denominados en su momento como "race films". Hasta finales de los años sesenta no podemos volver hablar de ningún otro ejemplo con la excepción de producciones independientes, casi marginales (Narcea, 2015). Hasta la Blaxploitation los y las afrodescendientes quedaban relegados a personajes secundarios en películas para blancos.

In order to reach a mass audience, people of color, women, and the queer community have had to work through an almost exclusively hetero, white male industry in order to secure funds for production and to ensure distribution. In this context, many actors and actresses of color have often had to make the difficult choice between playing roles that confirmed or perpetrated common stereotypes or not working at all. (Terry, 2012, p.79)

La lucha por los derechos civiles en los años sesenta y la concientización social ante la discriminación posibilitó filmes como To Sir, with Love (1967) o In the Heat of the Night (1968) con el comedido Sidney Poitier. "Las películas de Poitier se dirigían al público blanco y, si acaso, a los ciudadanos negros de las más altas clases sociales" (Narcea, 2015, p.3). No había transgresión ni se revestía la trama de una estética propia, exclusiva y distintiva de la comunidad. Poitier podía ir tranquilamente a tomar el té con bizcochitos al jardín de Katharine Hepburn y Spencer Tracy.

La constante necesidad de Hollywood por diversificar y masificar las audiencias se nutrió de la popularidad del Black Power a fines de los sesenta dando así inicio al nuevo género. Cabe mencionar también la creciente presión de las organizaciones civiles y sindicales por incrementar los empleos para los afroestadounidenses tanto delante como detrás de cámara (Quinn y Krämer, 2006). Sweetback's Baadasssss Song (1971 dirigida por Melvin Van Peebles) se convirtió en la primera película Blaxploitation genuina y en un éxito. Unos meses después llegaría Shaft (1971 dirigida por Gordon Parks) que estuvo entre las veinte películas más taquilleras de 1971 arrojando una ganancia de más de seis millones de dólares (ibíd.).

With Black stars, and most often, Black writers, directors, and sometimes even producers, these films made large profits for movie studios and entertained Black American audiences who were excited to finally see representations of themselves on screen in leading roles. (Guerrero, 1993 citado por Harris y Mushtaq, 2013, p.30) 
La Blaxploitation abrazó todo tipo de géneros, aunque la mayoría de las películas pertenecía al policial o de acción, y trataban temas urbanos y callejeros. Introdujo un nuevo estilo, con una insólita estética integral sobre dirección, fotografía, arte y musicalización. Las películas estaban protagonizadas por un héroe o una heroína negros, social y políticamente comprometidos, y sexualmente liberados. Los personajes secundarios también eran de raza negra, y los villanos (si eran blancos mejor) eran derrotados por el héroe/ heroína tras ejercer rigurosa violencia. También se incluyen problemáticas típicas de la comunidad como la persecución/exclusión racial y la brutalidad policial. Los personajes de la Blaxploitation tomaban la justicia en sus propias manos para enfrentar la pobreza y el crimen, para resolver problemas creados por el racismo institucionalizado y por un sistema legal corrupto (Robinson, 1998 citado por Terry, 2012). "Specifically, this success was due to the movie's portrayal of working-class Blacks in urban settings having to deal with issues of crime and drug abuse that were identified as problems created by the Whites" (Hartman, 1994 citado por Harris y Mushtaq, 2013, p.30).

Tanto en la comunidad negra como en la académica se ha dado el debate en torno al papel que jugaron estas películas. Algunos dirán, que al menos por un tiempo, la Blaxploitation ofreció una oportunidad para que actores y técnicos afroestadounidenses accedieran a trabajar en la industria, dando así vida a nuevos personajes que dejaban en el pasado estereotipos de sumisión y servilismo. Otros dirán "blacks not only failed to receive money but also had little to do with writing and production" (Terry, 2012, p.84). Esta última afirmación surge de un estudio realizado por The Chicago Reporter que luego de analizar un puñado de películas estableció que "only 4 of the 52 films in the study were produced, written, or directed by blacks" (ibíd., p.83-84). Y que en cuanto al remplazo de viejos estereotipos de sometimiento los nuevos no eran alentadores, se trataba de personajes súper erotizados, violentos, que vivían en guetos ficcionalizados dominados por las drogas, el alcohol, el proxenetismo y la prostitución, donde la ausencia de ley era una constante. Con esta paradoja a cuestas, la Blaxploitation puede ser considerada transformadora, fuente de empoderamiento o incluso revolucionaria, aunque también puede leerse como verduga, ya que por sus caricaturizaciones del Black Power y de la vida diaria de las comunidades afroamericanas se sumaba a los problemas coyunturales que debilitaban al movimiento.

La cuestión es que muchas de estas películas eran realizadas por grandes compañías pertenecientes a blancos que se quedaban con las ganancias. American International Pictures, por ejemplo, fue la productora de Coffy (1973) y Foxy Brown (1974). Compañías que invertían muy poco dinero y recibían enormes dividendos. Sweet Sweetback's Baadasssss Song, Shaft y Super Fly (1972 dirigida por Gordon Parks) fueron filmadas por directores negros pero financiadas por productoras blancas. Super Fly, a modo de caso, fue rodada con menos de ciento cincuenta mil dólares y recaudó casi treinta millones (Terry, 2012). Todo ese dinero caía en manos y bolsillos blancos.

With many films featuring pimps and drug dealers - typically antiheros - as heroes, and police and other governmental officials (most often White) as villains, many Black American organizations such as The National Association for the Advancement of Colored People (NAACP) and the Congress of Racial Equality 
(CORE), as well as Black churches and cultural institutions, criticized these films. (Guerrero, 1993 citado por Harris y Mushtaq, 2013, p.30-31)

Las clases medias y altas condenaron los estereotipos negativos que la Blaxploitation presentaba en pantalla, aunque esto solo reflejaba el rechazo que sentían hacia el Black Power en general. Este sentimiento también puede atribuirse a la división generacional, mientras los más jóvenes disfrutaban de la idea de tener personajes asesinando policías y políticos corruptos blancos, los más viejos se unieron emprendiendo varios boicots alegando que se degradaba a la comunidad negra (Terry, 2012).

Aún así, estas películas lograron solidificar y crear una identidad afroamericana en el imaginario popular. El líder de los Panteras Negras, Huey Newton, consideró a Sweet Sweetback's Baadasssss Song como "la primera película revolucionaria negra" (ibíd.).

Ya luego, mediando la década, muchos estudios dejaron de apoyar las películas de la Blaxploitation, un poco por desinterés al darse cuenta de que no las necesitaban para llegar al gran público, ya que los tanques como The Godfather (1972) o The Exorcist (1973) alcanzaban a las audiencias blancas y negras por igual, y un poco por las presiones de los grupos más conservadores. Hacia finales de los setenta el género se fue extinguiendo hasta desaparecer.

Sin embargo, el legado de la Blaxploitation perdura, y como veremos más adelante su influencia se volverá determinante para futuras producciones gracias a los cambios introducidos en torno a las representaciones raciales, lo genérico propiamente dicho y la estética en general, y por supuesto, aquellos viabilizados por las heroínas negras de acción.

\section{Representaciones y representaciones}

Históricamente, los blancos siempre han sido retratados como la raza dominante, y por el contrario, la representación negra a menudo ha sido sesgada bajo los auspicios de la subordinación, especialmente en el cine (Hooks, 1996). Los negros se convirtieron culturalmente en el "otro" y las películas se utilizaron para crear y mantener una identidad racial de sometimiento a través de diversas representaciones en cuanto a género y sexualidad (Hooks, 1996; Brooks y Hebert, 2006 citados por Harris y Mushtaq, 2013). Nos centraremos en los arquetipos negros, negativos, racistas y deshumanizados, ya que creemos que estas imágenes proporcionan importante información sobre las novedades que aporta la Blaxploitation a la pantalla estadounidense.

Para los hombres, el Sambo o "the coon" es la representación del vago, escandaloso y despreocupado. Suele tener características físicas exageradas, labios gruesos y nariz grande, y a menudo se lo ve comiendo sandías o robando gallinas. Los dueños de esclavos lo usaban para justificar la explotación (Bogle, 1973 citado por Harris y Mushtaq, 2013). Otra imagen de la masculinidad es el "buck", negro rebelde que rehúsa someterse a la autoridad blanca. Las representaciones de las mujeres negras en el cine hasta el momento no habían sido mejores que las de los hombres. Mammy es una mujer corpulenta, de piel oscura, con un vestido suelto tipo batón y delantal, a veces lleva un pañuelo en la cabeza, asexuada, un personaje que se ocupa de las tareas domésticas, de la cocina y de los niños (Anderson, 
1974; Bogle, 1973 citados por Harris y Mushtaq, 2013). Se popularizó luego de The Birth of a Nation (1915) y Gone with the Wind (1939), esclava de las plantaciones del Sur, leal a la familia de blancos a la que pertenece -similar a la caricatura de "Uncle Tom"-, sobremanera sumisa ante sus amos blancos a quienes sirve alegremente.

Sims (2006) refiere a una "exotic other" introducida en los años veinte con apariciones esporádicas hasta los cuarenta. De piel clara, delgada, rasgos finos, cabello lacio, y eso la convierte en una "outsider" tanto entre negros como blancos. La "exotic other" se llevaba la peor parte de los guiones al igual que la "tragic mulatta". La etiqueta de "tragedia" estaba atada al mestizaje y su inhabilidad para reconciliarse con su herencia.

La imagen de Jezebel es otra representación reservada para las mujeres negras. Es la antítesis de Mammy, su sexualidad está exacerbada y aquí es importante el matiz racial. Según Sims (ibíd.) habitualmente las mujeres blancas eran representadas en las películas como modelo de auto control, modestia, pureza, pero las mujeres negras por el contrario, podían representarse como promiscuas incluso depredadoras sexuales. Así, la industria del cine reforzaba el contraste entre los dos comportamientos y la noción que las audiencias blancas tenían sobre las mujeres negras.

Sims (ibíd.) menciona algunos estereotipos más: Aunt Jemima -bastante similar a Mammy pero relegada a la cocina-; y Sapphire maquillada en exceso, afilada y combativa verbalmente, de respuestas ocurrentes, cuyos modismos incluyen revolear las manos al hablar, o apuntar a su marido con el dedo - necesariamente tiene que haber un marido negro- mientras mantiene la otra mano en la cadera.

Todas estas imágenes ofrecen una visión distorsionada, reductora y racista en torno a la femineidad negra, y dieron lugar a mitos culturales asociados a que las mujeres afroamericanas eran o asexuadas o promiscuas. A modo de ejemplo, y recuperando el contexto de los sesenta y los setenta, el heroísmo de las mujeres activistas era una ausencia cinematográfica, y durante muchos años la industria no tuvo la menor intención de construir personajes multidimensionales o al menos de ofrecer una imagen alternativa.

Romper con estos estereotipos tan arraigados socialmente no sería una tarea fácil para las actrices que quisieran subvertir estas representaciones. "More importantly, the power structure of the film industry left black actresses at such a disadvantage that they had little choice concerning roles" (ibíd., p.4).

En los albores de la Blaxploitation las mujeres quedaban otra vez al margen. Los estándares masculinos eran los que dominaban. La mayoría de las películas presentaban a las mujeres de modo pasivo u objetivadas sexualmente, también como seres manipuladores en los que no se podía confiar. Sin embargo, Pam Grier, Tamara Dobson, Teresa Graves y Jeannie Bell pavimentaron el camino para nuevas heroínas y redefinieron a la mujer en la pantalla. La contribución de estas actrices a la cultura pop y al cine en general es monumental, alejándose de los papeles clásicos ya mencionados. Durante el período Blaxploitation la heroína de acción era una mujer común, hasta el momento ese lugar femenino no había sido explorado, antecedente valioso que sería retomado por el mainstream en la Ellen Ripley de Alien (1979), la Sarah Connor de Terminator (1984), Thelma y Louis (1991) (Sims, 2006). Y así, las mujeres de la Blaxploitation "... are the meanest chicks in town. They are brown sugar and spice but if you don't threat them nice they'll put you on ice!" - del póster de promoción de Foxy Brown. 


\section{I am looking in your big brown eyes: Coffy, Cleopatra Jones y Foxy Brown}

Hasta aquí hemos ubicado la Blaxploitation en un contexto de época, político, social y cultural. Queremos ahora emprender el camino de las heroínas negras de acción para comprender su particular aporte, no solamente por redefinir el modo en que las mujeres negras eran representadas en el cine sino también de las mujeres en general posibilitando proyecciones que se extenderían en el tiempo, porque huelga decir que durante el momento histórico de la Blaxploitation ni blancos ni negros estaban muy inmiscuidos en cuestiones de igualdad de género.

Aunque progresistas y renovadoras en muchos sentidos, las películas Blaxploitation a menudo retrataban a las mujeres como objetos sexuales. Sin embargo, Horton (1973 citada por Lawrence, 2008) describe la evolución, la irrupción de las heroínas negras de acción que desafiaban las representaciones tradicionales de Mammy, Jezebel, the tragic mulatta, etc., pero también los lugares comunes que ocupaban las mujeres en las películas protagonizadas por hombres.

In recent times the typical woman's role in black films has been a fairly predictable one: she's involved in a bedroom scene right at the beginning; she's making love with her man; his telephone rings. Right away, he has to get on the case. She asks him to stay, but no, he's got man's work to do-somewhere else. The woman then has little to do until the end of the movie when she welcomes her man, the hero, back home. In almost total disregard for black women, such films for the most part have shunned realistic images in favor of stereotypes. But new variations of old themes have seen women thrust into increasingly larger roles, and the magic formula reversed in some instances to give us the woman as hero or super-hero. (p.91)

Es verdad que las películas de la Blaxploitation, particularmente aquellas que se centraron en policiales o policiales de acción, proporcionaron héroes alternativos con quienes por primera vez el público podía identificarse, esos protagonistas se parecían a ellos. Como género, las películas de acción históricamente se habían limitado a intérpretes hombres y blancos, excluyendo tanto a hombres afroamericanos $-\mathrm{y}$ de cualquier otra etnia- como a mujeres. En la vieja escuela de películas de acción, las mujeres tendían a desempeñar el papel de rescatadas o a menudo solo de decoración (Sims, 2006).

Aunque siempre hubo heroínas en la historia del cine, el género de acción estaba reservado para "ellos". La heroína negra de acción era un personaje que los estudios más tradicionalistas habían considerado arriesgado para una película. Hasta la aparición y consecuente éxito de los personajes de Pam Grier para American International Pictures, las heroínas de acción no existían en el cine popular. Tanto Grier (protagonista de Coffy y Foxy Brown) como Dobson (protagonista de Cleopatra Jones) se erigen como heroínas de acción creando una gran demanda por actrices negras durante la Blaxploitation (Lawrence, 2008). A continuación, unas comprimidas sinopsis para compartir de qué van. 


\section{Coffy}

Coffy (1973 dirigida por Jack Hill) fue una de las primeras películas en presentar a una heroína negra. El argumento de Coffy gira en torno a la protagonista quien trabaja de día como enfermera y persigue su venganza contra traficantes de drogas por la noche. La película comienza cuando Coffy asesina de un escopetazo en la cara a un distribuidor menor responsable de convertir en adicta a su hermanita de once años. Más tarde, su amigo de la infancia que es un policía honesto, es golpeado brutalmente cuando amenaza con exponer a sus compañeros de la fuerza por actos de corrupción. Con la información que él le ha proporcionado, Coffy se infiltra en una red de narcotráfico y prostitución con el afán de desmantelarla. El resto de la película sigue a Coffy mientras ella se venga de los responsables de lastimar a su amigo y de introducir drogas en su comunidad. No queremos dejar de mencionar la traición de su pareja, un aspirante a congresista embanderado en la lucha por los derechos civiles, que la entrega literalmente a los villanos de los que es cómplice, y también termina con un escopetazo -y no en la cara justamente-.

Los críticos no la apreciaron por el contenido sexual explícito en el film, pero a pesar de las reseñas negativas Coffy generó ochenta y cinco mil dólares en su primera semana de exhibición, y la película continuó su triunfal carrera hasta que finalmente recaudó más de seis millones (Lawrence, 2008) demostrando que una película protagonizada por una heroína negra podía producir enormes ganancias.

\section{Cleopatra Jones}

Pocas semanas después de Coffy llegaría Cleopatra Jones (1973 dirigida por Jack Starrett). Warner Bros. se había dado cuenta de que las heroínas negras eran un éxito y vendían cantidad de entradas. La altísima Tamara Dobson era la protagonista. El argumento de Cleopatra Jones gira en torno a esta agente -no tan secreta- que trabaja para una organización gubernamental. La película comienza en Turquía donde Jones destruye una plantación de opio perteneciente a Mommy, la traficante de drogas más importante de Los Ángeles. La villana luego de enterarse de la aniquilación del campo, y a modo de venganza, hace arreglos con un policía corrupto para allanar un refugio de recuperación de adictos que es administrado por la pareja de Cleopatra Jones. Esto la lleva de regreso a Los Ángeles, donde busca a los policías responsables de la redada y destruye la organización del inframundo que maneja Mommy.

Además de recibir críticas positivas, Cleopatra Jones se lució en las taquillas. La película recaudó ciento diez mil dólares en su primera semana de estreno y finalmente reunió más de ocho millones (Lawrence, 2008).

\section{Foxy Brown}

Luego de Coffy, Grier protagoniza Foxy Brown (1974 también dirigida por Jack Hill), muy similar en tema y tono. Foxy Brown busca venganza luego del asesinato de su pro- 
metido, un oficial de la brigada de narcóticos. Foxy descubre que fue su propio hermano, que a su vez es un pequeño distribuidor de drogas local, quien delató a su novio con traficantes mayores para saldar una deuda. Los responsables del asesinato son una pareja que maneja un cartel de drogas y una red de prostitución por medio de la cual chantajean y compran jueces, congresistas y policías locales. Foxy se infiltra como prostituta pero es descubierta y encarcelada en una granja donde es drogada y violada. Logra escapar y pide ayuda a un grupo armado de su comunidad -que no se identifican como Panteras Negras pero casi-, y todos juntos invaden la finca de los villanos desbaratando la organización. No queremos dejar de mencionar aquí, la escena donde Foxy castra al villano jefe con un machete.

Foxy Brown se filmó con un presupuesto aproximado de quinientos mil dólares y recaudaría cerca de dos millones y medio (Imdb, s/f).

La aparición de estas protagonistas - mujeres, femeninas y negras- en policiales de acción es una significativa revisión de la tradicional concepción del género. Si bien las historias policiales de acción vienen de larga data en la literatura desembarcan tarde en el cine, y no fue hasta el estreno de Bullitt (1968 protagonizada por Steve McQueen) que las convenciones comenzaron a cristalizarse. Kaminsky (1985 citado por Lawrence, 2008) caracteriza así a los héroes "clásicos".

The protagonist is often a male who finds himself alone and in need of defining himself, or proving himself, through an act or acts of violence; The protagonist, as in most adventure tales, may be in his position out of choice or by chance, but when the physical challenge comes, he not only accepts it, but welcomes it. The protagonist must learn to exist without love as long as he is committed to his action of protective violence. Sex, if it exists at all -and it frequently does not for the protagonist in any normal way-is rapid, informal, and uninvolved. (p.79)

A su vez, King (1999 citado por Lawrence, 2008) encuentra en los policiales de acción una serie de elementos recurrentes.

Whether in law enforcement or civilian work, heroes protect people from harm. They face combinations of threats to their happiness: alienation from employees, estrangement from loved ones, and violence from criminals. Heroes join forces with fellow employees or bystanders (sidekicks) who give support. By the conclusions of these stories, many heroes have bettered their lives -reconciled with intimates, forged bonds with sidekicks, massacred enemies, or earned reprieve from communities they have saved. (p.79)

Otros ejemplos que podemos traer son The French Connection (1971 protagonizada por Gene Hackman), Dirty Harry (1971 protagonizada por Clint Eastwood) y Death Wish (1974 protagonizada por Charles Bronson).

Al igual que sus predecesores, nuestras tres heroínas enfrentan el delito, traficantes de drogas y la corrupción policial o política. "Her fight is directly related to improving 
the black community rather than reaffirming the dominant ideology's cultural values" (Lawrence, 2008, p.84).

Las tres se describen como mujeres habilidosas en el combate mano a mano, saben utilizar variedad de armas de fuego y disparan con puntería, hacen estallar cosas por los aires, conducen a alta velocidad -todo esto lo hacen mucho mejor que los malos-. Y a pesar de ser fuertes físicamente, sus personajes no están para nada masculinizados. Asimismo, se las presenta como sexualmente liberadas, contradiciendo las convenciones y desarticulando las construcciones anteriores de mujeres negras asexuadas o meramente objetos sexuales.

Sin embargo, y no queremos dejar de mencionarlas, existen un sinnúmero de críticas -algunas, no todas, a nuestro gusto someras- sobre estas películas.

Están las que provienen de grupos feministas que apuntan a la forma en que Grier y Dobson representan la feminidad, porque si bien desafían los roles asignados a las mujeres negras, todavía se ajustan a una noción muy "masculina" de liberación y empoderamiento (DeAnn Seifert, 2012). Desde estas miradas, paradójicamente actúan al mismo tiempo como heroínas de acción y objetos sexuales.

Podría sumarse que estas películas presentan antagonistas femeninas y dan como resultado una o varias escenas de pelea o confrontación entre mujeres, negándoles a los personajes una suerte de sororidad. Las heroínas que interpretan Grier y Dobson son incapaces de formar relaciones productivas con otras mujeres a pesar de que comparten intereses comunes (ibíd.). Además, si bien trabajan solas, en casi todos los casos acuden a hombres en busca de ayuda y anhelan una relación estable de pareja. Desde el punto de vista de estas críticas Coffy, Foxy Brown, Cleopatra Jones -y otras-, son funcionales a los líderes políticos masculinos, fortaleciendo el sexismo -producto del patriarcado capitalista y supremacista blanco-. Al minimizar la identificación con otras mujeres, las heroínas de acción se convirtieron en símbolos del Black Power, no de la liberación femenina (ibíd.).

El reproche político refiere a que, al igual que los personajes masculinos, estas nuevas heroínas convirtieron la liberación racial en una historia de venganza contra los blancos en lugar de una afrenta a la opresión sistematizada. Es decir, hay una falta de énfasis en las películas sobre la naturaleza institucional de la dominación, las estructuras que crean pobreza quedan intactas y la liberación se basa en la acción individual (Terry, 2012; DeAnn Seifert, 2012; Harris y Mushtaq, 2008).

La comunidad queer tampoco estaba contenta. La representación queer en las películas de la Blaxploitation se define por su contraparte heteronormativa, y serviría para reforzar la identidad de género de la protagonista y así dividir aún más a la comunidad negra y endurecer la homofobia (Harris y Mushtaq, 2008).

Un gran número de estudios mencionan a las villanas lesbianas caricaturizadas y brutales (DeAnn Seifert, 2012; Terry, 2012; Harris y Mushtaq, 2008). Consecuentemente, esto terminaría por fortalecer los parámetros de femineidad negra heterosexual demonizando -de modo bastante cuestionable- a aquellas otras orientaciones. Y esta es una constante en la Blaxploitation, los héroes de acción negros rayan la homofobia. 
The intersections of lesbianism, femininity, race and morality need to be fully examined in these films. Both Dobson and Grier's films present racialised lesbianism as linked to a binary struggle between good and evil and pit women against one another without apparent reason. (DeAnn Seifert, 2012, p.5)

Desde esta perspectiva, incluso el retrato de las antagonistas de Grier y Dobson, en lugar de empoderar a las mujeres creando hermandad y camaradería, beneficia a los hombres y perjudica los movimientos de liberación femenina (DeAnn Seifert, 2012; Harris y Mushtaq, 2008).

Todas estas críticas, valiosas y atendibles, son lecturas que construyen sentido pero que a su vez conviven con otras lecturas y otros sentidos. También diremos que las películas protagonizadas por hombres contenían la misma cantidad -o más- de y enumeramos: desnudos y escenas de sexo explícito, personajes homofóbicos y violentos, criminales, etcétera, etcétera, etcétera, pero los críticos se detuvieron al detalle en los aspectos más problemáticos de las películas protagonizadas por actrices (Terry, 2012).

Tal vez lo que falte para enriquecer el diálogo, es ponderar a las heroínas de acción por sus contribuciones al género. Si bien habían estado presentes aquí y allá en las películas de exploitation ganaron un sitio propio ante las audiencias luego de Coffy, seguida por Cleopatra Jones, Foxy Brown, T.N.T. Jackson (1974 protagonizada por Jeannie Bell), -y no dejemos en el tintero a Teresa Graves o Nichelle Nichols en televisión-.

Creemos que estas heroínas permiten una doble interpretación, negativa porque a menudo se mostraban, o mejor dicho, se ponían en situación de objetos sexuales -desnudas o con vestuarios que no dejaban nada a la imaginación-, y positiva porque tenían determinación y propósito, estaban dedicadas a eliminar las drogas y la corrupción de su comunidad, "luchaban contra el mal". "Sus métodos incluyeron el uso de sus cuerpos en esta cruzada" (Sims, 2006, p.9). Sus cuerpos, podemos entender, que más que objetos sexuales para hombres o víctimas del dominio masculino, se transforman en objetos de poder y por lo tanto ellas en sujetos poderosos, demostrando que no son sumisas ante las voluntades del macho de turno.

Estas heroínas de acción pioneras, además, allanan el camino y posibilitan la aparición de otras, la prueba está en que para nosotros espectadores 2020 ya no es provocador ver a una mujer en ese rol. Sin embargo, el contraste con los personajes de la Blaxploitation -corazón de este texto- es interesante y vale dedicarle algunos párrafos.

In many ways, race and class are a factor along with the fact that studios with larger budgets sometimes produce characters with more depth. What the action heroine lacked in blaxploitation was a depth found in Alien (1979) and what she lacked in her mainstream form was interesting, believable to a certain extent, everyday women. (Sims, 2006, p.9)

Y aquí identificamos un aporte clave de la Blaxploitation, que será plataforma de futuras heroínas de acción: las mujeres comunes que a fuerza de adversidad se ven obligadas a tomar "el problema" en sus propias manos, a "salir al ruedo" para cuidar a sus seres queridos y a su comunidad. Un paréntesis necesario porque no somos ingenuos, sabemos 
que ese lugar se construye a modo de reforzar los roles tradicionales de las mujeres como cuidadoras, en el subtexto yace "la maternidad" como experiencia central identitaria con valores ligados al altruismo y al cuidado de los otros. Este rasgo de nuestras heroínas negras se trasladaría luego a otras películas y a otras heroínas -la Ellen Ripley de Sigourney Weaver y la Sarah Connor de Linda Hamilton-. Para estas mujeres comunes siempre hay una provocación que las impulsa a reaccionar e involucra a sus familias, a su comunidad o a toda la raza humana. Y esto es parte del legado de la Blaxploitation, que no es poco.

Blaxploitation heroines were more developed then many of their male alter egos. [...] Grier managed to bring a depth to her heroines (especially in Coffy and Foxy Brown) that was lacking in many blaxploitation action movies centered on heroes. Weaver's Ellen Ripley is more complicated than Schwarzenegger and Willis heroes. Storyline plays an integral role, yes, but [...] what makes some action heroines compelling is how the actress chooses to portray the role, storyline, and other factors that are not necessarily tangible. Her appearance first in exploitation movies versus mainstream cinema is in itself interesting. (Sims, 2006, p.10)

El mainstreim además de la "mujer común" va a recuperar otro aporte de estas heroínas negras de la Blaxploitation: el lugar de proscritas. Las heroínas de Grier fueron atacadas por violentas, por la falta de remordimiento, por hacer justicia por mano propia y por no permitir que el sistema judicial castigue a los que han dañado a sus seres queridos. Sin embargo, unos veintiocho años después del estreno de Coffy, los personajes de Susan Sarandon y Geena Davis, mujeres suburbanas convertidas en forajidas, despertaron elogios tanto de críticos de cine, académicos y audiencias por igual. "Ironically, [...] a film starring two actresses as what could arguably be described as female versions of Bonnie and Clyde received acclaim for its "liberation" of women and their retribution was deemed justified" (Sims, 2006, p.10).

Más allá de las similitudes hay diferencias entre la heroína de acción de la Blaxploitation y su posterior prototipo. Las diferencias más obvias involucran raza y clase social. Pero en fin, gracias a Weaver, Hamilton, Sarandon y Davis, Drew Barrymore, Lucy Liu y Cameron Díaz (Charlie's Angels 2001 y 2003), Angelina Jolie (Tomb Raider 2001 y 2003) -y otras tantas que surgieron después de 1974 en televisión-, las heroínas de acción disfrutan de un gran éxito, han logrado su victoria. Sin embargo, desde el final de la Blaxploitation, las heroínas de acción afroamericanas han sido casi invisibles en el cine popular (ibíd.). Para cerrar el apartado nos parece imprescindible traer la palabra de Pam Grier sobre sus películas.

[My films] reflected the black community through language and music. We basically documented what was going on musically, religiously, and politically. I appreciate that happening now because now we can look back and see what we were about, and what we were saying. In the '70s we reaped the rewards of the '50s and '60s. It was a time of freedom and women saying that they needed empowerment. There was more empowerment and self-discovery than any other decade than I can remember. All across the country, a lot of women were Foxy Brown and 
Coffy. I just happened to be the first one that these filmmakers-Roger Corman, Jack Hill, Sam Arkoff, and AIP, found to portray that image. (Martinez et al. 1998, citado por Lawrence, 2008, p.91)

\section{Reflexiones finales}

Varios autores han reflexionado sobre la relación entre cine y sociedad: Marc Ferró, Pierre Sorlin, Siegfried Kracauer. Todos ellos nos animan a pensar que una película no solamente "se observa como obra de arte, sino como un producto, una imagen objeto cuya significación va más allá de lo puramente cinematográfico; no cuenta solo por aquello que atestigua, sino por el acercamiento sociohistórico que permite" (Ferró, 1995, p. 39). Si bien es cierto que el cine tiende a reproducir y reforzar estereotipos en relación a los devenires históricos, sociales, políticos y culturales, también es verdad que como mecanismo ideológico en sí mismo está inserto en procesos más amplios, arenas a su vez más amplias donde se ponen en escena y disputa distintos posicionamientos. Así, es capaz de posibilitar perspectivas plurales "sobre lo que una sociedad confiesa de sí misma y sobre lo que niega” (Sorlin, 1985, p.43).

Hasta la llegada de la Blaxploitation, los personajes reservados para las actrices afroamericanas estaban signados por su condición de mujeres negras con lo que esto significa dentro de la sociedad estadounidense, sexista, racista, marcada por profundas desigualdades. Es decir, respondían a mitos culturales y representaciones arraigadas de larga data que las encasillaban. Todos estaban muy conscientes del racismo y de la violenta anulación de la feminidad negra, dimensiones inescindibles porque "el patriarcado descansa sobre bases ideológicas semejantes a las que permiten la existencia del racismo" (Bairros, 2000, p.147). Creemos importante comprender la Blaxploitation en contexto, ya que es gracias a su desembarco en las pantallas que permitió a las espectadoras "to confront the painful distortions of stereotypical images while seeing glimpses of empowerment from the heroines' perspectives" (Sims, 2006, p.2). Hay que decir en este sentido, que las películas de Grier y Dobson en particular ofrecieron a muchas mujeres afroestadounidenses la posibilidad de identificarse con estas heroínas empoderadas, que al igual que ellas intentaban proteger a sus familias y ganarse el pan gracias a sus empleos, aunque al mismo tiempo tuvieran que "dismissing and ignoring the negative aspects of a character created by a producer who could not relate to the burdens endured by black women in a culture where gender and race often become determining factors in their status of some individuals" (ibíd., p.2).

Como dijimos antes, si bien el cine puede ser una herramienta para reforzar mitos y marginalizaciones, también puede ayudar a desmantelarlos. Pero "dismantling ingrained perceptions, particularly when they are so one-sided and have been held for generations at a time, is a large undertaking" (ibíd., p.2). Y esa fue la tarea hercúlea de Grier, Dobson, Graves, Bell -y muchas otras- que le demostraron a la industria su talla como artistas, la diversidad de roles que podían interpretar, que lograban enormes ganancias en la venta de entradas, que tenían más para ofrecer que los estereotipos "clásicos" que la industria había reservado históricamente para las mujeres negras. 
Hooks, Patricia Hill Collins, Jacqueline Bobo, and K. Sue Jewell [...] offers a full critique of Grier, Dobson, Graves, and Bell's lives as African American women attempting to make a living in an industry that allowed them limited entry and no creative freedom. Ironically, the film industry offers one of the few media outlets where African American women can change the cultural myths. (Sims, 2006, p.2)

Además, no es cierto que las actrices no tuvieran libertades creativas. Muchas de ellas participaron de las decisiones durante los procesos de producción. "This is particularly true of Grier and Graves, who were established enough to force directors -and, in Graves' case, a television production company- to make changes in their characters' personality make-up". (ibíd., p.3). Tal vez fuera esto lo que hiciera a sus personajes más auténticos. Antes de la década de 1970, las actrices afroamericanas eran racialmente estereotipadas, parecía que su lugar solo pertenecía a cocinas y despensas cuando no a burdeles, rara vez se las veía en personajes complejos y multifacéticos. Las películas de la Blaxploitation cambiaron eso para siempre al descubrirnos mujeres valientes que eran capaces de defenderse entre hombres y no dudaban en enfrentar al peligro para lograr su objetivo final: proteger a los suyos. Esas son las heroínas de acción que nos deja la Blaxploitation, que como todas las mujeres han recorrido un camino mucho más largo, más sinuoso, más difícil, más criticado que los hombres.

\section{Bibliografía}

Altman, R. (1999). Film Genre. Londres, UK: BFI.

Álvarez Ossa, L. (2015). Mujeres, pobres y negras, triple discriminación: Una mirada a las acciones afirmativas para el acceso al mercado laboral en condiciones de trabajo decente en Medellín (2001- 2011). Medellín, Colombia: Escuela Nacional Sindical.

Bairros, L. (2000). Nuestros feminismos revisitados. Política y Cultura, (14), 141-149. D.F., México: Universidad Autónoma Metropolitana.

Bellucci, M. (2013). Movimiento de Liberación de la Mujer en EEUU: «Ahora trabajamos para nosotras». Pikara Magazine. Disponible en https://www.pikaramagazine. com/2013/04/movimiento-de-liberacion-de-la-mujer-en-eeuu-ahora-trabajamos-paranosotras/ Fecha de consulta: 28/01/2020

Deann Seifert, M. (2012). Who's got the "reel" power? The problem of female antagonisms in blaxploitation cinema. Alphaville: Journal of Film and Screen Media, (4), 1-17.

Ferro, M. (1995). Historia contemporánea y cine. Barcelona, España: Ariel.

Goyeneche-Gómez, E. (2012). Las relaciones entre cine, cultura e historia: una perspectiva de investigación audiovisual. Palabra Clave, 15(3), 387-414. Bogotá, Colombia: Universidad de La Sabana

Harris, A. y Mushtaq, O. (2013). Creating Racial Identities Through Film: A Queer and Gendered Analysis of Blaxploitation Films. The Western Journal of Black Studies, 37(1), 28-38.

Hooks, B. (2004). Otras inapropiables. Feminismos desde las fronteras. Madrid, España: Traficantes de Sueños. 
Hooks, B. (2017). El feminismo es para todo el mundo. Madrid: Traficantes de Sueños.

Hooks, B. (1996). Reel to Real: race, sex and class at the movies. East Sussex, UK: Psychology Press.

Imdb (s/f). Foxy Brown (1974) Disponible en https://www.imdb.com/title/tt0071517/ Fecha de consulta: 8/02/2020

lawrence, N. (2007). Blaxploitation films of the 1970s: Blackness and genre. New York: Routledge.

Narcea, K. (2015). Los orígenes. Albedo media. Disponible en https://www.albedomedia. $\mathrm{com} /$ cultura/cinechrome/blaxploitation-los-origenes/ Fecha de consulta: 24/01/2020

Narcea, K. (2015). Ellas dan los golpes. Albedo media. Disponible en https://www.albedomedia.com/cultura/cinechrome/las-heroinas-de-blaxploitation/ Fecha de consulta: $24 / 01 / 2020$

Quinn, E. y Krämer, P. (2006). Blaxploitation. Contemporary American Cinema, 184-198. London: Open University Press.

Sims, Y. (2006). Women of Blaxploitation: How the Black Action Film Heroine Changed American Popular Culture. Carolina del Norte: McFarland \& Company.

Sorlin, P. (1985). Sociología del Cine. La apertura para la historia de mañana. D.F., México: Fondo de Cultura Económica.

Terry, J. (2012). Towards the Gendering of Blaxploitation and Black Power. Madison Historical Review, 9, 79-105. Disponible en htp://commons.lib.jmu.edu/mhr/vol9/iss1/5 Fecha de consulta: 1/02/2020.

\section{The Path of Black Heroines: Blaxploitation}

Abstract: In the United States feminism did not originate from the women that were more directly victims of the sexist oppression; mentally, physically and spiritually beaten daily; women without the necessary strength to change their life conditions" (Hooks, 2004, p.33). Feminist activists were white and wealthy class even as black women were a silent majority. Although many women were part of Black Power, the movement was defined and assembled in the media, the pop culture and the arts by men. These groups maintained a patriarchal organization; structures constituted by male leadership. They "realized of the nature of the male domination when participating in anti-classist and anti-racist spaces with men who spoke to the world about the importance of freedom despite subordinating the women among their own ranks" (Hooks, 2017, p.22). There was neither a place destined for black women amongst white feminists nor the Black Power of men.

"As a group, black women are in an unusual position in this society, because not only we are at the bottom of the occupational pyramid as a collective, but also our social status is lower than any other group. Being in this position, we endure the hardest of sexist, racist and classist oppression. [...] Black men can be victims of racism, but sexism allows them to act as exploiters and oppressors of women. White women can be victims of sexism, but racism allows them to act as oppressors of black people" (Hooks, 2004, p.49). 
In the late 60's, and from this socio-political context, Blaxploitation emerges in the American's cinemas that would replace old stereotypes of submission by new ones hypersexualized, violent, anti-social living in a fictionalized lawless communities controlled by corruption and vice, like a caricaturized version of Black Power that has been criticized in almost all its aspects as counterrevolutionary and antithetical to the liberation of the AfroAmerican community (Terry, 2012). But even the harshest critics vindicate the place of the black heroines among the violence and the stereotypes of Blaxploitation.

In the dawn of Blaxploitation, women were again left out. However, Pam Grier, Tamara Dobson, Teresa Graves y Jeannie Bell paved the way for new heroines and redefined the female role on the screen. The contribution of these actresses to pop culture and movies in general is monumental, walking away from classic roles as Mammy (slave in the Southern plantations performed household tasks as a maid or as a cook, fat and sexless) or as Sapphire (verbally combative, pointing at her husband with a finger and holding hip with the other hand), among many others (Sims, 2006).

During Blaxploitation, the action heroines was the everyday woman, until this moment that female role was absent in films, a valuable background which would be picked up by mainstream in the Ellen Ripley of Alien (1979), the Sarah Connor of Terminator (1984), Thelma y Louis (1991) (Sims, 2006).

We want to think films as a valuable point of analysis of history, historical record, a cultural artifact. Movies have the power to shape, reaffirm or simply deconstruct the perceptions on ethnicities, genres, classes and sexualities. As one of the most powerful communicative transmitters, movies played and still play an important part in cultural myths about the feminine.

Key words: Feminists movements - Black Power - Blaxploitation - black heroines stereotypes - cultural myths.

\section{O camino das heroínas negras: Blaxploitation}

Resumo: Nos Estados Unidos, o feminismo não emergiu de mulheres que foram mais diretamente vítimas da opressão sexista; mulheres espancadas diariamente, mentalmente, fisicamente e espiritualmente; mulheres sem a força necessária para mudar suas condições de vida" (Hooks, 2004, p.33). As ativistas feministas eram brancas e burguesas, enquanto as mulheres negras eram uma maioria silenciosa.

Embora muitas mulheres participassem do Poder Negro, o movimento foi definido e articulado na mídia, na cultura popular e nas artes pelos homens. Os grupos mantinham uma organização patriarcal, estruturas caracterizadas pela liderança masculina. Eles "tomaram consciência da natureza da dominação masculina quando militaram em espaços anti-classe e anti-racistas com homens que falaram ao mundo sobre a importância da liberdade enquanto subordinavam as mulheres em suas fileiras (Hooks, 2017, p.22). Não havia lugar para mulheres negras entre feministas brancas e Black Power masculino.

"Como grupo, as mulheres negras estão em uma posição incomum nesta sociedade, como não apenas nós, como coletivo, na base da pirâmide ocupacional, mas nosso status social é mais baixo do que em qualquer outro grupo. Ao manter essa posição, suportamos o peso 
da opressão sexista, racista e de classe. [...] Homens negros podem ser vítimas de racismo, mas o sexismo permite que eles atuem como exploradores e opressores das mulheres. As mulheres brancas podem ser vítimas de sexismo, mas o racismo lhes permite agir como opressores para os negros" (Hooks, 2004, p.49).

Nesse contexto político-social, a Blaxploitation surgiu no cinema americano no final da década de 1960, que substituiria velhos estereótipos de submissão por novos estereótipos de hipersexualidade, violência anti-social, comunidades sem lei, dominadas pela corrupção e pelo vício. Uma versão caricaturada do Black Power que tem sido amplamente criticada em quase todos os seus aspectos por ser contra-revolucionária e antitética à libertação da comunidade afro-americana (Terry, 2012). Mas mesmo os críticos mais severos reivindicam o lugar das heroínas negras entre a violência e os estereótipos de Blaxploitation.

No início dos filmes Blaxploitation, as mulheres estavam mais uma vez à margem. No entanto, Pam Grier, Tamara Dobson, Teresa Graves e Jeannie Bell abriram o caminho para novas heroínas e redefiniram as mulheres na tela. A contribuição dessas atrizes para a cultura pop e o cinema em geral é monumental, afastando-se de papéis clássicos como Mammy (escrava das plantações do sul que servia na casa fazendo tarefas domésticas ou como cozinheira gorda e assexuada) e como Safira (verbalmente combativo, gesticulando, apontando o dedo para o marido e a outra mão no quadril), entre muitos outros (Sims, 2006).

Durante o período de Blaxploitation, a heroína de ação era uma mulher comum, até agora aquele lugar feminino era uma ausência cinematográfica, um antecedente valioso que seria adotado pelo mainstream em Ellen Ripley, de Alien (1979), Sarah Connor, de Terminator (1984), Thelma e Louis (1991) (Sims, 2006).

Queremos pensar no cinema como um ponto valioso de análise da história, como um documento da época, como um artefato cultural. Os filmes têm o poder de moldar, reforçar ou desconstruir claramente as percepções sobre etnia, gênero, classe, sexualidade. Poderosos transmissores comunicacionais, filmes exibidos e ainda desempenham um papel importante nos mitos culturais sobre o feminino.

Palavras chave: Movimentos feministas - Black Power - Blaxploitation - heroínas negras; estereótipos - mitos culturais.

[Las traducciones de los abstracts fueron supervisadas por el autor de cada artículo] 